\section{IMPACT OF WAVES ON DANGEROUS STABILITY OF VESSELS ON THE OCEANIC ROUTE}

DOI 10.2478/ntpe-2018-0058

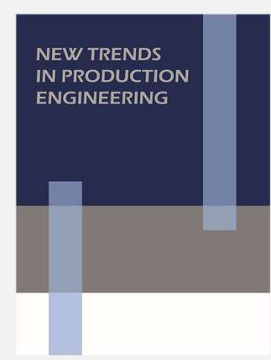

2018

Volume 1

Issue 1

pp. $469-477$

\begin{abstract}
Stability is one of the most important properties of the ship. The greatest influence on stability and thus on the possibility of loss of stability have the rolling of the ship on the wave. Mathematical models describing rolling on wave are complicated, and their solution, especially in the irregular wave, is only possible with numerical methods in the time domain. Large rolling, until the ship capsize, formation not only on the beam wave, but also on the following wave. Various models describing rolling (linear and nonlinear, regular and irregular wave, and constant or variable restoring moment) are presented. The predicted level hazard of stability of the ship depends on the direction of the wave and the cases where the level of hazard will be greatest.
\end{abstract}

Keywords: irregular wave, rolling of a vessel, stability on beam and following waves, variable righting moment

\title{
INTRODUCTION
}

Stability is the property of the ship to oppose heeling moments and allows for basic functions to be performed under these conditions. Stability depends on the geometry of the submerged hull part, the position of the center of mass of the ship, and the wind and wave parameters.

When the ship sailing is in real weather (wind, wave), the heeling moment is dynamic (depends on time), so the ship's heel is dynamic. The simultaneous impact of the wind (eg. moment from the gusts) and the wave (motions of the ship) can significantly increase the dynamic heel of the ship until to capsize.

The stability of the ship is influenced by rolling, and when calculating the values of the rolling, it should be taken into account that:

- rolling are coupled to swaying and yawing (the yawing has a minimal effect on rolling),

- rolling largely depend on non-linear damping moment and non-linear restoring moment,

- under the influence of the remaining motions, mainly of the heaving and the shape of the surface of the wave, relative motions are created, the volume and shape of the underwater ship's hull are changed, and the effect of the change in the variable value of the restoring moment,

- under the influence of wind and wave, the lateral force of the drift is generated, the speed of the drift is influenced on rolling.

Taking into account all these phenomena in a mathematical model that describes rolling, this model is very complicated, and its solution, even on a regular wave, is only possible by numerical computer simulation in the time domain.

The rolling of the ship is influenced by the parameter and direction of the wave relative to the ship, the speed of the ship, the geometric parameters and the weight distribution of the ship, and additional damping devices, such as bilge keel.

Dynamic stability of the ship is a complicated phenomenon and, therefore, in the literature, hazard stability analyzes are usually carried out from simplified mathematical models describing 
individual cases of rolling (linear and non-linear rolling, regular and irregular wave, constant or time-varying restoring moment), (Acanfora and Cirillo, 2017, Dudziak, 1988, Hu et al., 2017, PRS, 2020, Szozda, 1997, Wawrzynski and Krata, 2016).

The article presents the problem of calculating rolling of ships of different models (linear and nonlinear, regular and irregular). The influence of the wave direction, wave parameters and the influence of the variable at the time of restoring on the possibility of the occurrence of stability hazards has been analyzed.

\section{ROLLING OF THE SHIP AT STEADY RESTORING MOMENT}

When sailing of the ship on waves, where relative motions are small, and the wave parameters do not cause significant changes in the ship's hull underwater volume, it can be assumed that the restoring moment does not depend on time. Then the simplest nonlinear equation of the rolling of the ship is as follows (Dudziak, 1988):

where:

$$
\left[I_{x x}+m_{\phi \phi}(\Phi)\right] \ddot{\Phi}-M_{D}(\dot{\Phi})-M_{R}(\Phi)=M_{E}(t) \text {, }
$$

- $I_{x x}$ moment of inertia of the mass of the ship relative to the longitudinal axis $x$,

- $m_{\phi \phi}(\Phi)$ the moment of inertia of the hydrodynamic mass depends on the angle of heel of the ship (in the linear motions theory, this moment does not depend on the angle of the heel),

- $M_{D}(\dot{\Phi})$ nonlinear damping moment of the rolling of the ship, this moment is most often represented in the form (Dudziak, 1988):

$$
M_{D}(\Phi) \cong-\left[N_{\phi \phi}(\Phi) \dot{\Phi}+W_{\phi \phi} \dot{\Phi}|\dot{\Phi}|\right],
$$

- $N_{\phi \phi}(\Phi)$ potential damping coefficient of rolling depending on the heel angle of the ship (in the linear motions theory this coefficient does not depend on the heel),

- $W_{\phi \phi}$ coefficient of non-linear part of the damping moment (viscous damping, vortex, and from the bilge keel),

- $M_{R}(\Phi)$ nonlinear restoring moment whose value does not change over time, Fig. 1,

- $\Phi, \dot{\Phi}, \ddot{\Phi}$ respectively: roll, speed and acceleration of rolling,

- $M_{E}(t)$ excitation moment of the rolling from the wave.

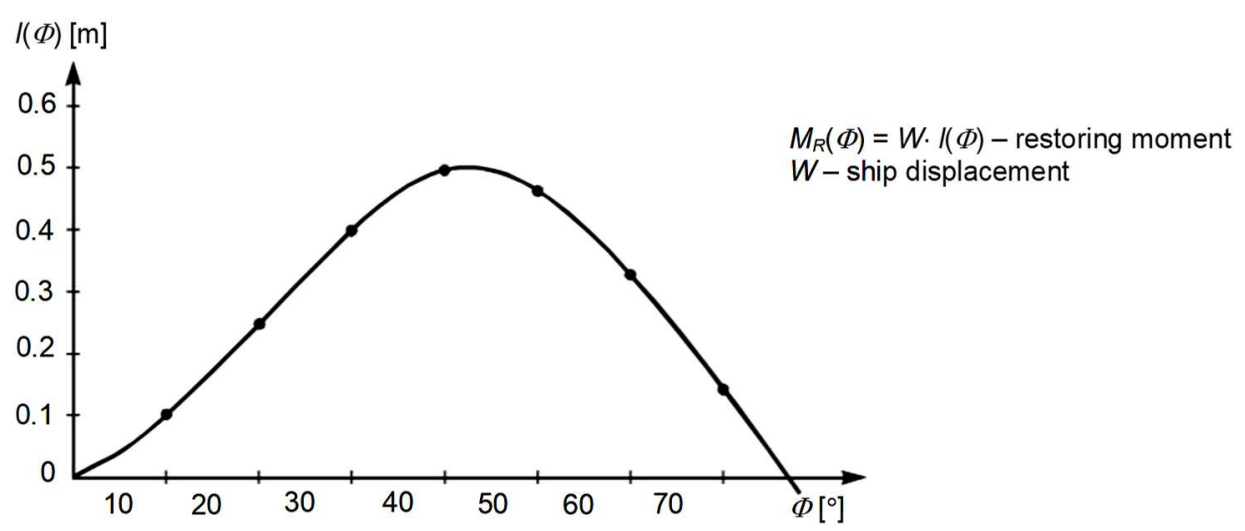

Fig. 1. An example of the static righting lever $I(\Phi)$ independent of time.

In the general case, due to the damping moment $M_{D}(\dot{\Phi})$ and the restoring moment $M_{R}(\Phi)$, even assuming that $m_{\phi \phi}$ and $N_{\phi \phi}$ do not depend on rolling, the excitation moment $M_{E}(t)$ comes from the regular wave. There is no analytical solution to this problem, equ. (1). If the excitation moment $M_{E}(t)$ is from an irregular wave, then the determination of rolling from the equ. (1) is only possible with the numerical solution in the time domain (computer simulation of rolling) (Szelangiewicz, 2003).

An example of numerical solution of the time-domain equation (1) for the excitation moment $M_{E}(t)$ from the regular wave is shown in Fig. 2. 


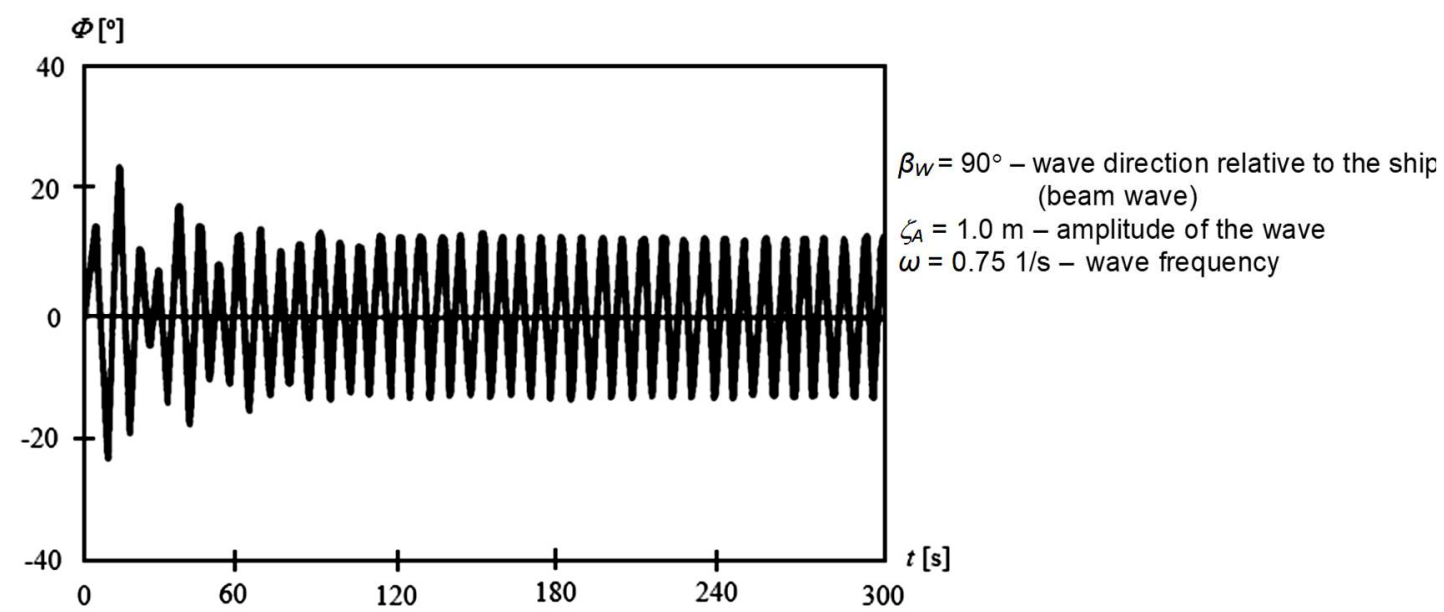

Fig. 2. The simulation in time-domain of the rolling from regular excitation moment (beam wave).

The results of the test of the numerical method used are shown in Figure 3, (Szelangiewicz, 2003). Equation (1) has been replaced by a linear equation and analytical solution, and by a numerical method in the time domain. The roll transfer function obtained in both cases is almost identical. An example of the calculated roll transfer functions $Y_{\Phi_{\alpha}}\left(\omega_{E}\right)$ for different wave directions relative to the ship is shown in Figure 4.

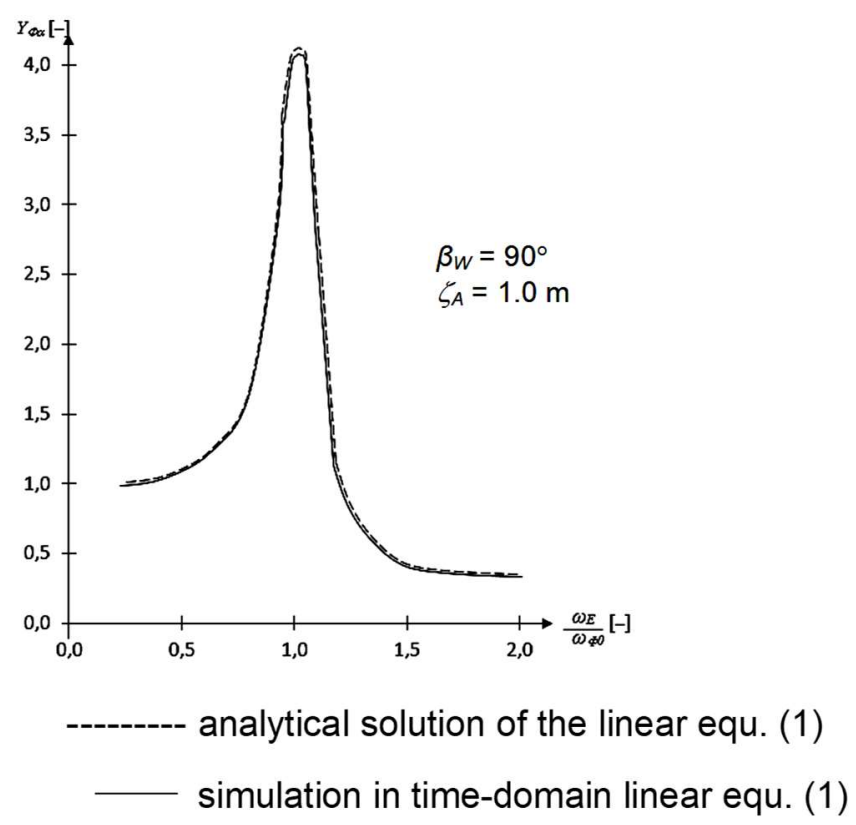

Fig. 3. Comparison of roll transfer function $Y_{\Phi \alpha}$.

Fig. 3 and 4 show the rolling resonance of the ship, when the natural rolling frequency of the ship's $\omega_{\Phi_{0}}$ is:

$$
\omega_{\Phi 0} \approx \omega_{E}
$$

where:

- $\omega_{E}$ the encounter frequency rolling:

- $\omega_{E}=\omega-k V \cos \beta_{W}$,

- $k$ wave number,

- $V$ speed of the ship. 


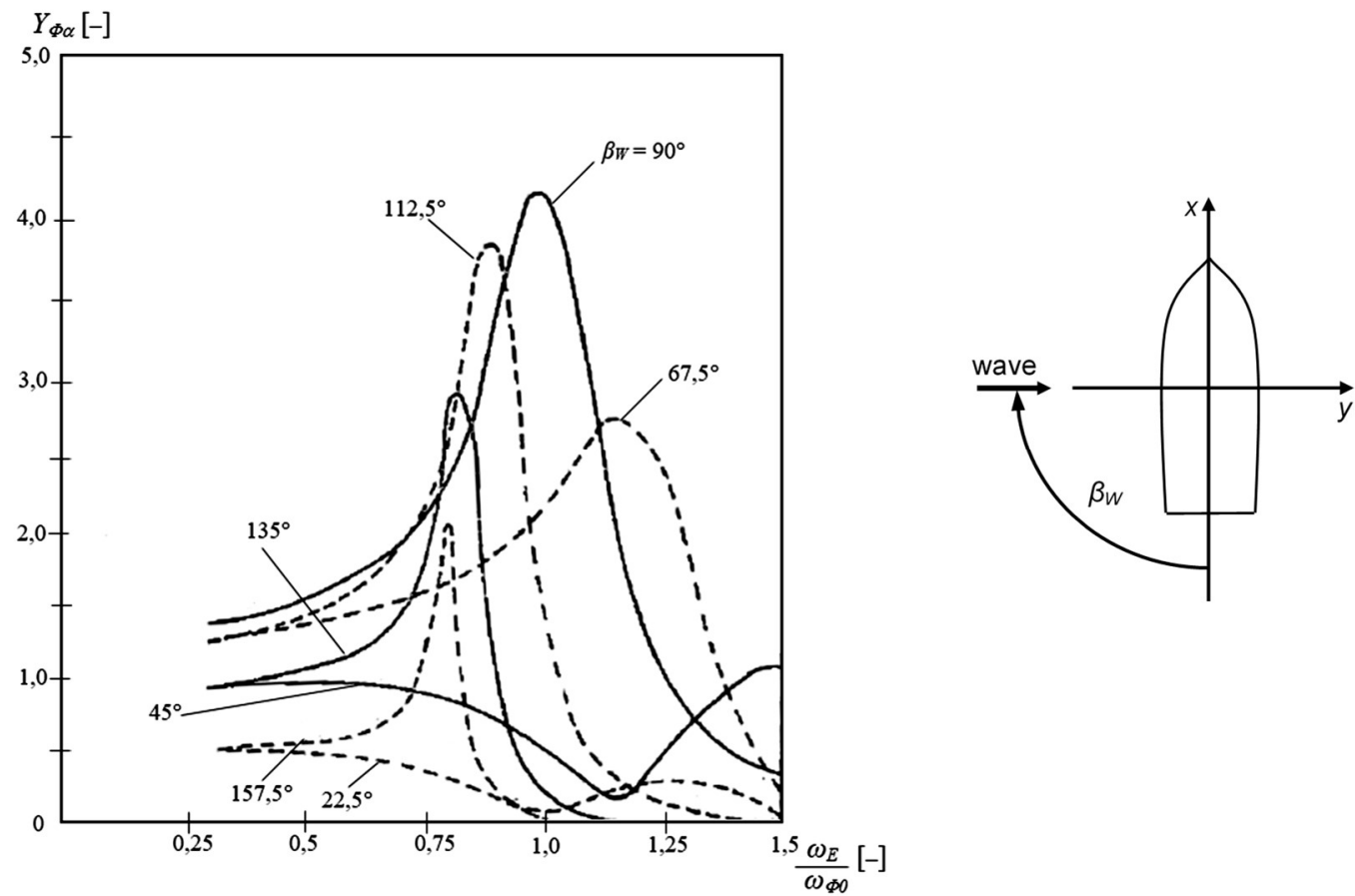

Fig. 4. Influence of wave direction $\beta_{w}$ on roll transfer function for ship sailing at speed $V=8.27 \mathrm{~m} / \mathrm{s}$.

When $V=0$ or $\beta_{W}=90^{\circ}$ is $\omega_{E}=\omega$. The largest resonance (the greatest increase in amplitude $\Phi_{A}$ of rolling) is on the beam wave when $\beta_{W}=90^{\circ}$. The magnitude of this resonance (and thus the amplitude of roll) mainly depends on the damping of the rolling, the moment $M_{D}(\dot{\Phi})$ in equation (1).

Then equation (1) was solved numerically in the time domain at the random excitation moment $M_{E}(t)$ from the irregular wave with the parameters: significant wave height $H_{S}=2.64 \mathrm{~m}$, characteristic time $T=6.72 \mathrm{~s}$, spectral density of wave energy: JONSWAP. The calculation results are shown in Figure 5, (Szelangiewicz, 2003).

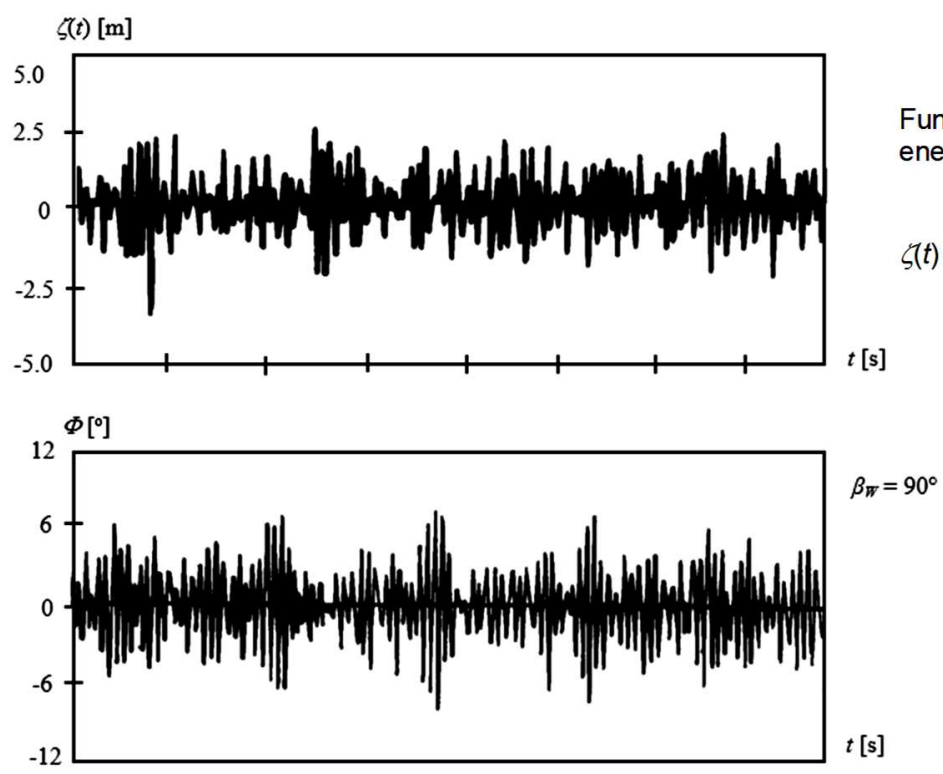

Fig. 5. Simulation of random waves and random rolling on the beam wave.

By performing such computer simulations (numerical solutions of equation (1) in the time domain on the irregular wave) for different wave directions relative to the ship and the random wave parameters, significant amplitudes of roll $\Phi_{\mathrm{A} 1 / 3}$ were obtained, Fig. 6 . 


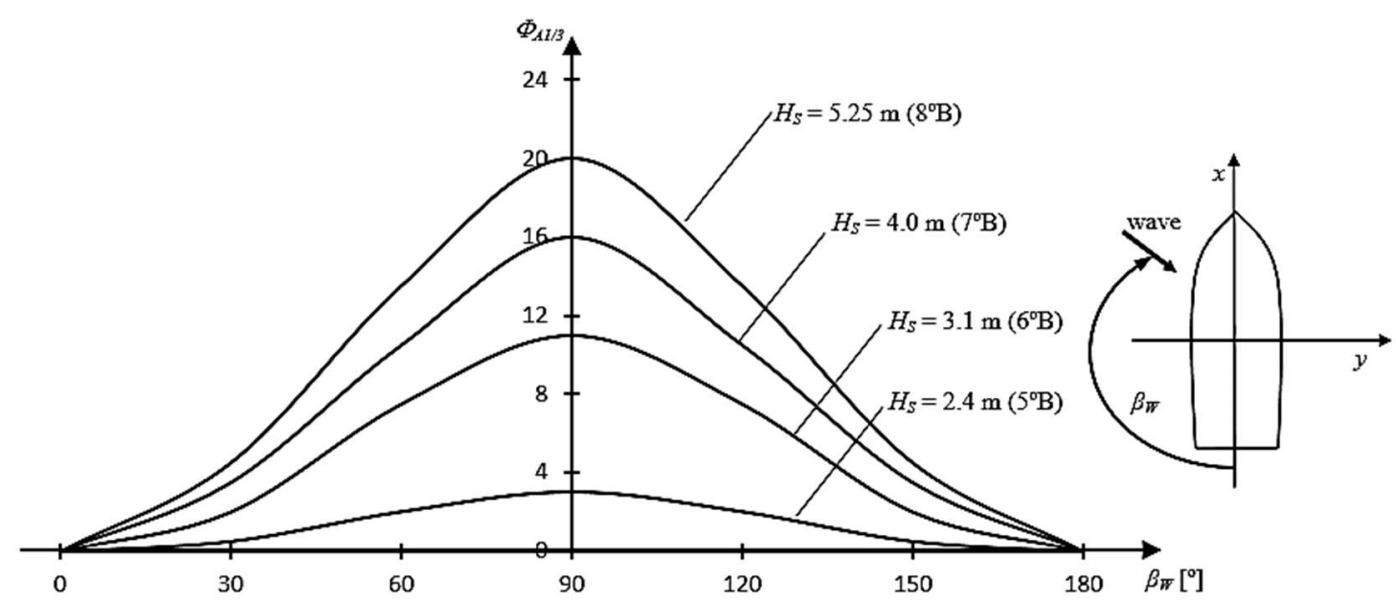

Fig. 6. Influence of sea state and wave direction on significant roll amplitudes.

\section{INFLUENCE OF WAVES AND MOTIONS OF THE SHIP FOR RIGHTING MOMENT}

On calm water the righting moment is due to hydrostatic pressure acting on the wetted surface of the hull of the heeled ship (for a given heel angle, the righting moment on calm water is independent of time, Fig. 1). On the wave, the hydrodynamic pressure is from the undisturbed wave and from the disturbance that the ship enters the wave. When the ship sailing of on wave, the relative motion of the ship and form of wave cause changes in the volume and shape of the wetted part of the ship's hull (Fig. 7) and changes in the geometric characteristics on which the restoring moment depends.

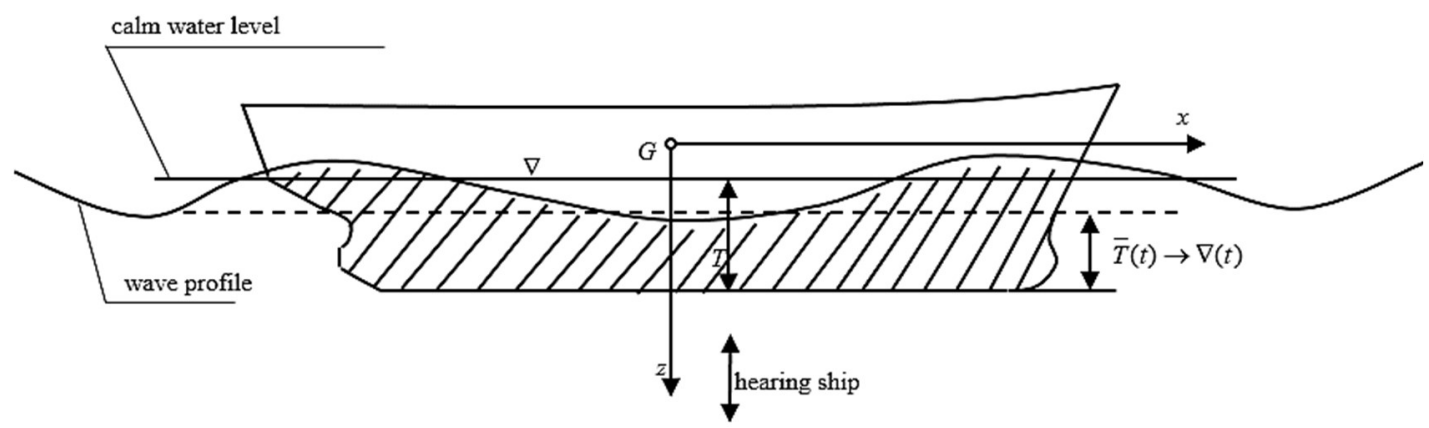

Fig. 7. Change in volume and shape of the underwater ship's hull due to relative motion (mainly heaving) and wave form (regular longitudinal wave).

Explanations:

$T, \nabla$-draught and volume of the underwater hull of the ship on calm water,

$\bar{T}(t)$ - average momentary draught of the ship on the wave,

EIID - the momentary shape and volume,

$\nabla(t)$ of the underwater ship's hull on the wave.

Relative motions cause that while the ship is sailing on the wave, the restoring moment depends on time. It can be approximated as the sum of the righting moment in calm water and the corrections resulting from the wave action (Dudziak, 1988):

where:

$$
M_{R}(\Phi, t)=M_{R 0}(\Phi)+\delta M_{R 1}(\Phi, t)+\delta M_{R 2}(\Phi, t)+\delta M_{R 3}(\Phi, t)
$$

- $M_{R o}(\phi)$ the restoring moment on calm water,

- $\delta M_{R 1}(\phi)$ correction due to centrifugal forces that occur as a result of the ship's orbital velocity in the waves,

- $\delta M_{R 2}(\phi, t)$ correction taking into account the effect of changes in the volume of the underwater hull caused by relative motions (in particular, heaving),

- $\delta M_{R 3}(\phi, t)$ correction resulting from changes in the shape of the underwater hull caused by waves (changing the shape of the underwater hull causes the absolute value of the righting levers to change),

- $\phi$ heel angle of the ship (on the wave is it roll), 
- $t$ time.

Correction $\delta M_{R 1}$ occurs when a beam or oblique wave occurs on the ship, and its stability effect on large transport vessels is small.

Correction $\delta M_{R 2}$ (resulting from the change in the volume of the underwater part of the hull) is present for all wave directions and the maximum values are for beam and following waves. Correction $\delta M_{R 3}$ has the highest value on the following wave. Although these two corrections occur on the longitudinal wave, however, they depend on the rolling and their influence on the transverse stability of the ship can be large.

The corrections of $\delta M_{R 1}, \delta M_{R 2}, \delta M_{R 3}$ of the righting moment, for a ship in a specific loading state and sailing at a velocity $V$ for $\beta_{W}$ in relation to the wave direction, can be made dependent on the regular wave, ie. the amplitude $\zeta_{A}$ and the frequency $\omega$ or length $\lambda$. The value of these corrections (either positive or negative) will vary oscillatively over time as the value of the ordinate of the regular wave that changes these corrections changes.

You can generally write down that the variable time in the righting moment on a regular wave equals:

where:

$$
M_{R}(\Phi, t)=M_{R}^{0}(\Phi)+W h_{A} \Phi \cos \left(\omega_{E} t+\varepsilon_{h}\right)
$$

- $M_{R}^{0}(\Phi)$ righting moment on calm water, whose value varies with the angle $\Phi$ of the ship's heel,

- $W$ ship displacement,

- $h_{A}$ amplitude of the initial metacentric height, which results from the influence of wave and motions of the ship at the righting moment,

- $\omega_{E}$ encounter frequency,

- $\varepsilon_{h}$ phase angle between wave and metacentric height changes.

An example of the change of the righting lever of the regular following wave $\left(\beta_{W}=0^{\circ}\right)$ with the specified amplitude $\zeta_{A}$ and length $\lambda$ is shown in Figure 8.

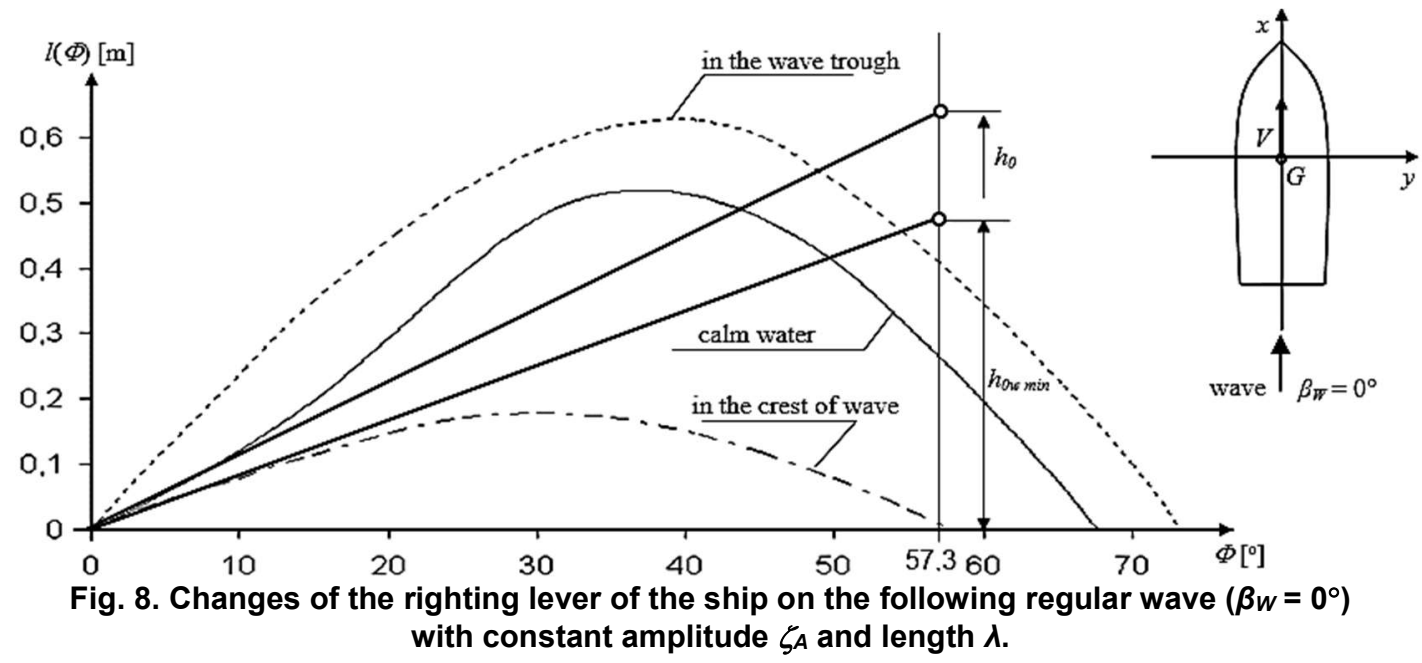

\section{CHANGE OF METACENTRIC HEIGHT ON IRREGULAR WAVE}

On the irregular (random) wave will be continuous random changes of the righting lever curve. Since there is a specific relationship between the righting lever curve and the metacentric height, the changes in the righting lever curve can be approximately replaced by a certain "virtual" metacentric height whose maximum and minimum values will oscillate around the $h_{0}$ value for calm water. The instantaneous value of the "virtual" metacentric height will be equal:

$$
h_{0 w}(t)=h_{0}+\Delta h_{w}(t)
$$

where:

$\Delta h_{w}(t)$ is the change in the metacentric height of the ship on the wave. 
The amplitude of the oscillation of the metacentric height $\Delta h_{A w}$ will also depend on the ship's parameters (loading state, velocity $V$ and direction of motion with respect to the wave $\beta_{W}$ ) and from the ship's motions wave: amplitude $\zeta_{A}$ and length $\lambda$ (or frequency $\omega$ ).

By applying the linear motions theory of the ship on the wave, you can determine the frequency characteristic of the metacentric height changes while sailing on a regular wave:

$$
Y_{h \zeta}\left(i \omega / V, \beta_{W}, \Phi\right. \text {, ship loading condition), }
$$

then, knowing the spectral density function of the irregular wave energy $S_{\zeta \zeta}(\omega)$, the variation of the metacentric height changes in the irregular wave:

$$
D_{h}=\int_{0}^{\infty}\left|Y_{h \zeta}(i \omega)\right|^{2} \cdot S_{\zeta \zeta}(\omega) \mathrm{d} \omega .
$$

Given the variance $D_{h}$, from the Rayleigh distribution, we can determine the mean change in metacentric height with the assumed probability of exceeding when sailing on the irregular wave (given by the spectrum $S_{\zeta \zeta}(\omega)$ ):

$$
\overline{\Delta h_{w}}=\sqrt{8 \ln \frac{1}{p}} \cdot \sqrt{D_{h}}
$$

where $p$ is the probability of exceeding the value $\overline{\Delta h_{w}}$.

\section{ROLLING OF THE SHIP AT A VARIABLE AT THE TIME OF RIGHTING MOMENT}

Taking into account in equation (1) the time-varying righting moment of given equation (6) we obtain a nonlinear parametric equation describing the rolling of the ship:

$$
\left[I_{x x}+m_{\phi \phi}(\Phi)\right] \ddot{\Phi}-M_{D}(\dot{\Phi})-\left[M_{R}^{0}(\Phi)+W h_{A} \Phi \cos \left(\omega_{E} t-\varepsilon_{h}\right)\right]=M_{E}(t)
$$

Equation (11) is often represented in linear form, and after corresponding transformations is reduced to the Mathieu equation. Although the Mathieu equation is linear, its solution is hard. Because the hazard stability of the ship is at high amplitudes, parametric rolling should be calculated from the nonlinear equation (11) using numerical methods (Acanfora and Cirillo, 2017, Dunne and Wright, 1985, Faizarano and Mulk, 1994, Hu et al., 2017 and Liaw, 1993). However, in order to solve the equation (11) even when excitation moment from a regular wave, the amplitude of the metacentric height change $h_{A}$ and the phase angle $\varepsilon_{h}$ in the wave on which the vessel flows must first be calculated. The $h_{A}$ amplitude and the resulting changes in metacentric height depend on many parameters, but for a particular ship the resulting parametric rolling depends mainly on:

- speed of the ship $V$,

- wave direction relative to the ship $\beta_{W}$,

- wave parameters: length $\lambda$ and amplitude $\zeta_{A}$.

Based on the analysis of simplified equations describing the rolling of the ship, one can list the most dangerous situations where the stability of a ship can be lost until it capsize under the influence of large rolling:

1. On the beam wave $\left(\beta_{W}=90^{\circ}\right.$ or $\left.270^{\circ}\right)$, when formation rolling resonance $\omega_{E}=\omega=\omega_{\Phi 0}$ or resonance of the heaving: $\omega_{E}=\omega=\omega_{z 0}$, the resonance of the heaving is affected by the correction $\delta M_{R 2}$.

2. On the following wave $\left(\beta_{W}=0^{\circ}\right)$ when:

- wave length $\lambda \cong(1.0 \div 1.2)$ of the length of the vessel $L$ and velocity of the vessel $V \cong$ $C_{W}$ (wave phase velocity), the vessel sailing at the velocity of the wave and when it is on the crest of the wave the righting moment has a very small value the ship can heel and capsize,

- the ship sailing more slowly than the wave moves, $V<C_{W}$, formation the resonance of rolling parametric at $\omega_{E} \cong 2 \omega_{\Phi 0}$, the resulting rolling may be so large that the ship capsize,

- the ship is overtaken by a wave $\left(V<C_{W}\right)$ of length $\lambda \cong(1.5 \div 2.0) L$, when the stern is at the crest of the wave, the vessel loses the stability of the straight line, it may be quarter or beam wave, which may cause overturning get the ship (broaching).

3. If the vessel is sailing on the head wave $\left(\beta_{W}=180^{\circ}\right)$, the resulting encounter frequency $\omega_{E}$ is large enough that no resonance and no stability hazard exists. 
On the basis of the above considerations and conditions, it is possible to present areas of high stability of a ship during sailing on wave - Fig. 9.

The greatest parametric rolling, equ. (11), does not always result in beam wave, but may occur on the following wave but with such parameters as the greatest changes at righting moment.

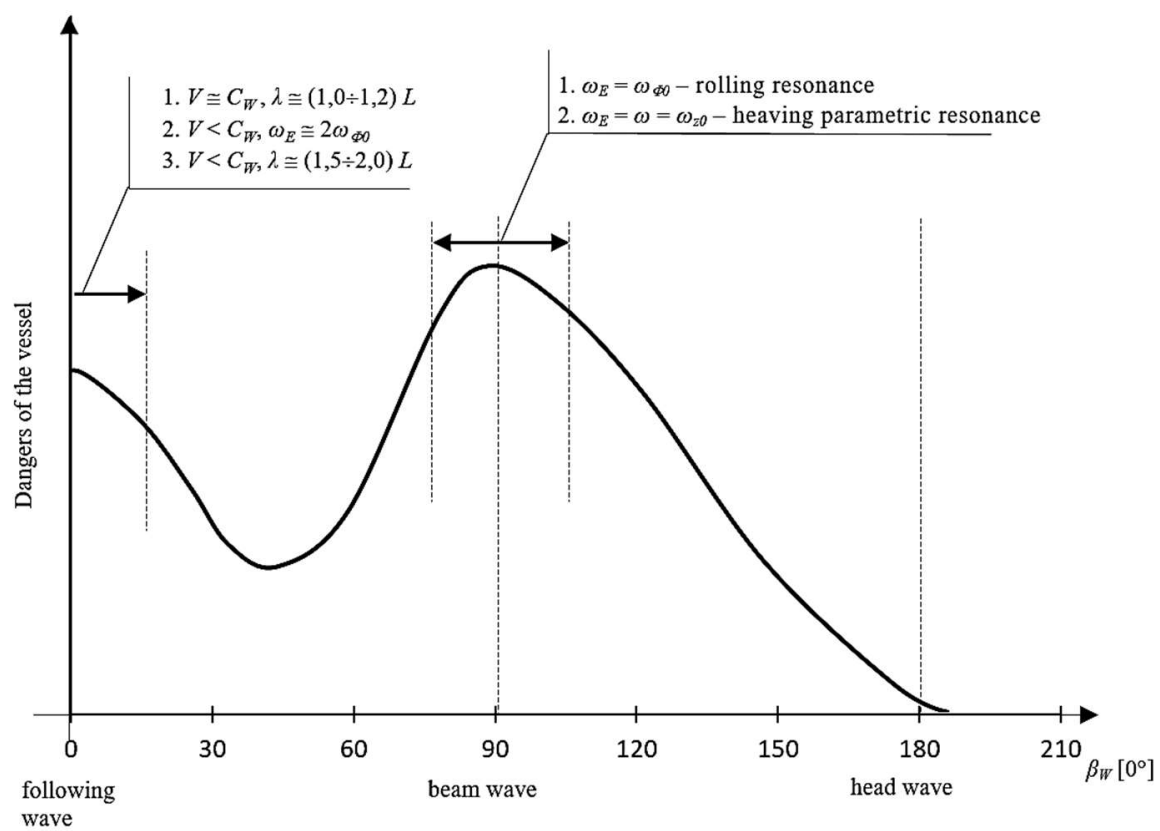

Fig. 9. Estimated from the analysis of the corresponding equations and observed on ships stability status depending on the speed of ship $V$ and wave direction relative to the ship $\beta_{W}$.

\section{CONCLUSIONS}

1. In this paper, the problem of mathematical modeling and calculation of rolling of the ship, which has a decisive influence on the stability hazard, is presented.

2. Two cases have been discussed:

- the rolling of the ship when the non-linear restoring moment can be assumed to be constant over time,

- the rolling of the ship when the restoring moment is variable over time.

3. The conditions are shown when large changes occur at the time of restoring moment - which parameters determine the high stability risk.

4. The predicted state of the ship's stability risk depends on the speed of the ship $V$ and the wave direction relative to the ship $\beta_{W}$.

5. Attention was paid to the direction in which research should be carried out to calculate the rolling of the ship for various vessel parameters (length $L$ and velocity $V$ ) and wave parameters (length $\lambda$ and phase velocity $C_{W}$ ) at which a high stability hazard due to large rolling.

\section{REFERENCES}

Acanfora, M. and Cirillo, A. (2017). On the intact stability of a ship in head and following sea: an analysis of the dynamic roll angle due to sudden heeling moments. Journal Of Marine Science And Technology. 22(4). pp. 734-746.

Dudziak, J. (1988). Teoria okrętu. Gdańsk: Wydawnictwo Morskie.

$\mathrm{Hu}, \mathrm{K} .$, Wang, R., Ma, S. et al. (2017). Numerical modelling and study of parametric rolling for c11 containership in regular head seas using consistent strip theory. BRODOGRADNJA. 68(3). pp. 135-156.

Przepisy klasyfikacji i budowy statków morskich, część IV. Stateczność i niezatapialność. (2002). Gdańsk: PRS.

Szozda, Z. (1997). Stability Control of a Ship in Service. Zeszyty Naukowe Wyższej Szkoły Morskiej w Szczecinie. 53. pp. 169-176. 
Wawrzynski, W. and Krata, P. (2016). On ship roll resonance frequency. OCEAN ENGINEERING. 126. pp. 92-114.

Szelangiewicz, T. (2003). Podstawy teorii projektowania kotwicznych systemów utrzymywania pozycji jednostek pływających. Gdańsk: Wydawnictwo Budownictwo i Żegluga.

Dunne, J.F. and Wright, J.H. (1985). Predicting the Frequency of Occurrence of Large Roll Angles in Irregular Seas. TRINA, 127. pp. 233-245.

Faizarano, J. and Mulk, M.T. (1994). Large Amplitude Rolling Motion of an Ocean Survey Vessel. Marine Technology. 31(4). pp. 278-285.

Liaw, C.Y. (1993). Dynamic Instability of a Parametrically Excited Ship Rolling Model. In: Proceedings of the Third, International Offshore and Polar Engineering Conference. Singapore: International Society of Offshore and Polar Engineers.

Date of submission of the article to the Editor: 06/2018

Date of acceptance of the article by the Editor: 09/2018 